pressure measurement technique; and provides some form of regular professional supervision. The hypertensive population in general practice is heterogeneousfor example, in terms of age, comorbidity, and individual preferences. ${ }^{10}$ That many patients declined the offer to join the self measurement group in the study by McManus and colleagues hampered recognitions of this heterogeneity. A practical solution could be to offer self monitoring only to those most likely to practise it, probably minimising the risk of anxiety and other adverse effects among patients. Testing patients' motivation and allocating a treatment strategy accordingly, along the lines of the stages of change model used in risk factor management, could facilitate selection. ${ }^{11}$

Given that the current value of self monitoring of blood pressure remains uncertain, we recommend carefully designed experiments within the broader

1 Williams B, Poulter NR, Brown MJ, Davis M, McInnes GT, Potter JF, et al. Guidelines for management of hypertension: report of the fourth working party of the British Hypertension Society, 2004-BHS IV.J Hum Hypertens $2004: 18: 139-85$.

2 Collins R, Peto R, MacMahon S, Hebert P, Fiebach NH, Eberlein KA, et al. Blood pressure, stroke, and coronary heart disease. Part 2. Short-term
reductions in blood pressure: overview of randomised drug trials in their reductions in blood pressure: overview of randomised drug trials in thei epidemiological context. Lancet 1990;335:827-38.

3 Wolf-Maier K, Cooper RS, Kramer H, Banegas JR, Giampaoli S, Joffres $\mathrm{MR}$, et al. Hypertension treatment and control in five European countries, Canada, and the United States. Hypertension 2004;43:10-7.

4 Fahey T, Schroeder K, Ebrahim S. Interventions used to improve control of blood pressure in patients with hypertension. Cochrane Database Syst Rev 2003;CD005182.

5 O'Brien E, Asmar R, Beilin L, Imai Y, Mancia G, Mengden T, et al. Practice guidelines of the European Society of Hypertension for clinic, ambulatory and self blood pressure measurement. J Hypertens 2005;23:697701. context suggested in the Cochrane review by Fahey and colleagues. ${ }^{4}$ Consultation at the practice at least once a year seems necessary to check whether the conditions for successful self measurement of blood pressure are still in place. But practice based self monitoring, as introduced by McManus and colleagues, offers a greater safety net. It allows active participation by patients without losing professional supervision, which may prove to be a considerable advantage over self monitoring at home.

J Carel Bakx senior researcher

(c.bakx@hag.umcn.nl)

Mark C van der Wel GP registrar

Chris van Weel professor

Department of General Practice, Radboud University Nijmegen Medical Centre, PO Box 9101, 6500 HB Nijmegen, Netherlands

6 McManus RJ, Mant J, Roalfe A, Oakes RA, Bryan S, Pattison HM, et al. Targets and self monitoring in hypertension: randomised controlled trial and cost effectiveness analysis. BMJ 2005:331:493-6.

7 Cappuccio FP, Kerry SM, Forbes L, Donald A. Blood pressure control by home monitoring: meta-analysis of randomised trials. BMJ 2004;329:145. 8 Staessen JA, Den Hond E, Celis H, Fagard R, Keary L, Vandenhoven G, et al. Antihypertensive treatment based on blood pressure measurement at home or in the physician's office: a randomized controlled trial. JAMA 2004;291:955-64.

9 Campbell NC,.Murchie P. Treating hypertension with guidelines in general practice. BMJ 2004:329:523-4.

10 Little P, Barnett J, Barnsley L, Marjoram J, Fitzgerald-Barron A, Mant D Comparison of acceptability of and preferences for different methods of measuring blood pressure in primary care. BMJ 2002;325:258-9.

11 Verheijden MW, Bakx JC, Delemarre IC, Wanders AJ, van Woudenbergh NM, Bottema BJ, et al GPs' assessment of patients' readiness to change diet, activity and smoking. Br J Gen Pract 2005;55:452-7.

\title{
Coronary heart disease in women
}

\section{Is underdiagnosed, undertreated, and under-researched}

$\mathrm{C}$ oronary heart disease remains the leading cause of death in men and women worldwide, and cardiovascular deaths exceed the number of deaths from all cancers combined. In the United Kingdom, coronary heart disease causes almost 114000 deaths a year, and one in six occurs in women. ${ }^{1}$ In the UK and Europe, one woman dies every six minutes of heart disease and in the United States, one every minute. Moreover, in Europe, cardiovascular disease kills a higher percentage of women (55\%) than men $(43 \%))^{2}$ Yet coronary heart disease is still considered a disease of men.

Many women are unaware that coronary heart disease is their main killer; their biggest fear is breast cancer. Even more worrying, however, is the apparent lack of awareness of cardiovascular disease in women among healthcare professionals. At the time of presentation with heart disease, women tend to be 10 years older than men, and at the time of their first myocardial infarction they are usually 20 years older. ${ }^{34}$ As coronary heart disease is a disease of the older woman, many women believe that they can postpone attempts to reduce their risk.

Risk factors for heart disease differ between the sexes. For example, women with diabetes have 2.6 times the risk of dying from coronary heart disease risk among men with diabetes. ${ }^{3}$ Similarly hypertension is associated with a twofold to threefold increased risk of coronary events in women. ${ }^{3}$ Low concentrations of high density lipoprotein seem to be a better predictor of coronary risk in women than high concentrations of low density lipoprotein. ${ }^{3}$ Furthermore, high levels of triglyceride are associated with greater risk among women than men. ${ }^{3}$

Women and men with heart disease tend to differ in their presenting symptoms, their access to investigations and treatment, and their overall prognosis. Women may have more atypical symptoms than men-such as back pain, burning in the chest, abdominal discomfort, nausea, or fatigue-which makes the diagnosis more difficult. Women are less likely to seek medical help and tend to present late in the process of their disease. They are also less likely to have appropriate investigations, such as coronary angiography and, together with late presentation to hospital, this can delay the start of effective treatment.

There are particularly clear sex differences in patients undergoing coronary revascularisation: mortality in women is notably higher. ${ }^{5-7}$ At the time of presentation with coronary artery disease, women are more likely to have comorbid factors such as diabetes mellitus, hypertension, hypercholesterolaemia, peripheral vascular disease, and heart failure. ${ }^{8}$ In addition, 
women's coronary vessels tend to be smaller than those of men, which makes them more difficult to revascularise percutaneously as well as surgically. ${ }^{8}$ And, because of late presentation, women more often need urgent intervention.

Although the absolute mortality for women undergoing percutaneous and surgical revascularisation seems to be improving, ${ }^{79}$ it remains higher than for men. Most studies have shown that mortality in hospital is similar in men and women undergoing coronary revascularisation after adjustment for the increase in overall risk among women. ${ }^{79}$ The wider use of drug eluting stents and adjunctive medical therapy such as glycoprotein $\mathrm{Ilb} / \mathrm{III}$ inhibitors, as well as improved techniques such as off-pump surgery and minimally invasive coronary surgery, may help to improve outcomes in women having coronary revascularisation. ${ }^{10}{ }^{11}$ For example, paclitaxel eluting stents reduce clinical and angiographic restenosis in both sexes. ${ }^{10}$ And a recent large study found that women who had off-pump coronary artery bypass surgery had $32.6 \%$ lower mortality, a $35.1 \%$ lower complication rate owing to bleeding, a $118.6 \%$ lower rate of neurological complications, and a $49.3 \%$ lower rate of respiratory complications than women having on-pump surgery. ${ }^{11}$

Women continue to be under-represented in research on heart disease. They account for less than $30 \%$ of the participants in most studies and trials in cardiology. It is difficult, therefore, to draw conclusive evidence on managing cardiovascular disease in women. Despite differences between the sexes in risk factors, presentation, and response to treatment, women continue to receive similar treatments to men on the basis of trials that include mainly male participants. To remedy this, participants' sex must be considered in the design and analysis of cardiology studies.

Better awareness and education, earlier and more aggressive control of risk factors, and appropriate access to diagnosis and treatment are desperately needed to tackle this potentially fatal disease. To raise awareness the American Heart Association has launched the extensive "Go Red for Women Campaign," and in 2004 the association published guidelines for preventing cardiovascular disease in women, ${ }^{12}$ while the US National Heart, Blood, and Lung Institute runs "The Heart Truth Campaign."13 The European Society of Cardiology is soon to publish a scientific statement on the management of women's heart disease and will launch this month its Women at Heart Initiative to alert medical professionals to the burden and underappreciation of heart disease in women.

\section{Ghada W Mikhail consultant cardiologist}

North West London Hospitals and St Mary's Hospital Trusts, London NW10 7NS

(g.mikhail@btopenworld.com)

Competing interests: None declared.

1 Petersen S, Peto V, Scarborough P, Rayner M, British Heart Foundation Health Promotion Research Group. Coronary heart disease statistics 2005. Oxford: British Heart Foundation, 2005. www.heartstats.org/temp/ CHD_2005_Whole_spdocument.pdf (accessed 15 Aug 2005).

2 Petersen S, Peto V, Rayner M, Leal J, Luengo-Fernandez R, Gray A. European cardiovascular disease statistics. 2005 edition. Oxford: British Heart Foundation, 2005. www.heartstats.org/uploads/documents\%5CPDF.pdf (accessed 15 Aug 2005)

3 Wenger NK. Coronary heart disease: The female heart is vulnerable. Prog Cardiovasc Dis 2003;46:199-229.

Von der Lohe E. Coronary heart disease in women. Berlin, Heidelberg, New York: Springer, 2003.

5 Kelsey SF, James M, Holubkov AL, Holubkov R, Cowley MJ, Detre KM. Results of percutaneous transluminal coronary angioplasty in women: 1985-1986 NHLBI coronary angioplasty registry. Circulation 1993;87: $720-7$

6 Vaccarino V, Lin ZQ, Kasl SV, Mattera JA, Roumanis SA, Abramson JL, et al. Gender differences in recovery after coronary artery bypass surgery. JAm Coll Cardiol 2003;41:307-14.

7 Peterson ED, Lansky AJ, Kramer J, Anstrom K, Lanzilotta MJ. Effect of gender on the outcomes of contemporary percutaneous coronary intervention. Am J Cardiol 2001;88:359-64.

8 Jacobs A K. Coronary revascularization in women 2003. Sex revisited. Circulation 2003;107:375-7.

9 Jacobs AK, Johnston JM, Haviland A, Brooks MM, Kelsey SF, Holmes DR, et al. Improved outcomes for women undergoing contemporary percutaneous coronary intervention: a report from the national Heart, Lung, and Blood Institute Dynamic Registry. J Am Coll Cardiol 2002;39:1608-14. 10 Lansky AJ, Costa RA, Mooney M, Midei MG, Lui HR, Strickland W, et al. Gender-based outcomes after paclitaxel-eluting stent implantation in patients with coronary artery disease. J Am Coll Cardiol 2005;45:1180-5.

11 Mack MJ, Brown P, Houser F, Katz M, Kugelmass A, Simon A, et al. On-pump versus off-pump coronary artery bypass surgery in a matched sample of women. A comparison of outcomes. Circulation 2004:110: 110(11Suppl1):II1-6.

12 Mosca L, Appel L J, Benjamin EJ, Berra K, Chandra-Strobos N, Fabunmi RP, et al. Evidence-based guidelines for cardiovascular disease prevention $\mathrm{RP}$, et al. Evidence-based guidelines for car

13 National Heart, Lung, and Blood Institute. The heart truth: a national awareness campaign for women about heart disease. www.nhlbi.nih.gov/ health/hearttruth/ (accessed 11 Aug 2005).

\title{
Clean drinking water for homes in Africa and other less developed countries
}

\author{
Flocculant-disinfectant treatment with bleach is effective and acceptable
}

$\mathrm{M}$ ore than 1 billion people in developing countries lack access to safe water, and 2.2 million die annually of diarrhoea. ${ }^{1}$ Unfortunately, communities where diarrhoea is a leading cause of morbidity and mortality often lack the capacity and the resources to establish and sustain centrally purified water free from sewage. ${ }^{2}$

Contamination of water during collection, transport, and storage at home presents a serious risk to health for millions of households in developing countries. Several studies have shown an increased risk of diarrhoea because of inadequate water storage. ${ }^{3}$ Regardless of where or how the water is collected, storage vessels with wide openings such as pots or buckets are easily contaminated with faeces, through the introduction of cups, dippers, or hands. Water might also be contaminated by flies, cockroaches, and rodents.

Several organisations have adopted a three pronged approach for treating water at the point of use. ${ }^{4}$ This includes using simple household bleach (sodium hypochlorite) to disinfect the water, using narrow mouthed storage vessels, and working with
Papers p 478

BMJ 2005;331:468-9 